Sharif University of Technology
Scientia Iranica
SCIENTIA
I RAN I C A

\title{
Simultaneous train rescheduling through cancelling, delaying, and re-ordering policies: Three-phase solution method with guaranteed optimality
}

\author{
M. Tamannaei ${ }^{a, *}$, M. Saffarzadeh ${ }^{\mathrm{b}}$, A. Jamili ${ }^{\mathrm{c}}$ and S.E. Seyedabrishami ${ }^{\mathrm{b}}$ \\ a. Faculty of Transportation, Isfahan University of Technology, Isfahan, Iran. \\ b. Department of Civil and Environment Engineering, Tarbiat Modares University, Tehran, Iran. \\ c. Department of Industrial Engineering, University of Tehran, Tehran, Iran.
}

Received 3 May 2015; received in revised form 1 November 2015; accepted 28 November 2015

\section{KEYWORDS}

Train rescheduling;

Railway;

Solution method;

Branch-and-bound;

Incident.

\begin{abstract}
In this article, a new approach is presented to solve the double-track railway rescheduling problem, when an incident occurs into one of the block sections of the railway. The approach simultaneously considers three rescheduling policies: cancelling, delaying, and reordering. To find the optimal conflict-free timetables compatible with the approach, a mathematical model and an exact three-phase solution method are proposed. The method is based on Branch-and-Bound (B\&B) algorithm. The lower bound consists of two cost parts: the cost of deviation from the primary timetable and the cost of train cancellation. To generate an appropriate upper bound, the method exploits an innovative algorithm called "Local Left Shifting". A heuristic beam search technique is also developed for tackling the large-scale problems. An experimental analysis on two double-track railways of the Iranian network indicates that the proposed solution method provides the optimal solution in much shorter time, compared with the time taken to solve the mathematical model by CPLEX software. Based on the findings of this research, it is possible to optimally retrieve the primary timetable after incident occurrence during a pre-determined time horizon.
\end{abstract}

(C) 2017 Sharif University of Technology. All rights reserved.

\section{Introduction}

The essential purpose of the railway transportation studies is to schedule the train movements with a minimum of investment cost, personnel, equipment, energy consumption, operating, and maintenance costs $[1,2]$. A reliable scheduling timetable helps keep costs down and allows the managers to optimally operate due to different constraints $[3,4]$. However, in real-time, an

*. Corresponding author.

E-mail addresses: m.tamannaei@gmail.com ( $M$.

Tamannaei); saffar_m@modares.ac.ir (M. Saffarzadeh);

a_jamili@ut.ac.ir (A.Jamili);

seyedabrishami@modares.ac.ir (S.E. Seyedabrishami) unforeseen event may disrupt an optimal timetable, and thereupon result in monetary compensations due to the delays imposed to both passenger and freight trains. A train rescheduling system should be able to revise the schedule and find a new conflict-free timetable compatible with the real-time status. The new timetable not only must be able to minimize the total traveling costs, but also to minimize the costs of deviating from the primary timetable [5]. Several strategies may be applied to reschedule the trains and resolve the conflicts such as delaying trains, cancellation/partial cancellation of services, route diversion, inclusion of additional services, changing the platform, relocating the stops, reshuffling train orders, etc. $[6,7]$. The train rescheduling is currently an active 
research area in operations research [8]. In a wide literature on rescheduling railway services, IP and MIP mathematical models have been used to formulate the problems $[9,10]$, because they are able to accommodate the linearity of the objective functions and constraints. However, there are a lot of studies focused on proposing heuristic solution methods to solve the train rescheduling problems. Also, to handle the disturbances, some authors proposed to use decision support systems [11-13]. An overview of recovery models and algorithms for real-time railway disturbance and disruption management is presented by Cacchiani, et al. [8]. The following are some recent literature reviews associated with train rescheduling:

D'Ariano et al. [14] proposed a detailed alternative graph model for the train dispatching problem. To resolve the conflicts in real-time, they developed a system to predict the potential conflicting routes, based on an accurate monitoring of train positions and speeds. Their iterative rescheduling procedure provided the final solution, which is a conflict-free schedule that respects the signalling and safety constraints. Tornquist and Persson [15] presented a model and B\&B solution method for the railway traffic rescheduling problem, considering the large number of railway tracks and segments and each rail network direction. An MIP model representing the disturbed n-tracked network is solved using CPLEX software. Four strategies were evaluated by their optimality, speed, and sensitivity to the problem size. Burdett and Kozan [16] developed techniques for scheduling additional train services in an existing timetable. To solve the problem, they utilized constructive algorithm and meta-heuristic techniques that operate upon a disjunctive graph of train operations. Sato and Fukumura [17] studied on train crew rescheduling. They formulated the problem as an IP model with set-covering constraints. Cacchiani and Caprara [18] presented a heuristic algorithm for scheduling extra freight trains on a railway network, in which passenger trains already have a prescribed timetable that cannot be changed. D'Ariano [19] developed a real-time train dispatching support system by means of alternative graphs. The objective was to minimize the train consecutive delays at selected points in the case of service disruption. The system is capable of being an efficient tool for real-time traffic management, even in the case when the actual timetable is in conflict or deadlock. Mu and Dessouky [20] focused on rescheduling freight trains. They developed two mathematical formulations: one assumes that the path of each train is given and the other one relaxes this assumption. Several heuristics based on mixtures of the two formulations were proposed. An approach proposed by Caimi et al. [21] attempted to reschedule trains by a discrete-time control aiming at maximizing train punctuality and reliability. Corman et al. [22] proposed a bi-objective rescheduling model of minimizing train delays and missed connections. Sato and Fukumura [23] focused on rescheduling of freight train locomotives when dealing with a disrupted situation. They formulated and solved the problems by column generation. Albrecht et al. [24] presented a verification rescheduling model that simultaneously considered track maintenance and trains. Their examples were based on maintenance scenarios for Queensland railways. Dündar and Şahin [25] developed a decision support tool based on Genetic Algorithm (GA) for conflict resolutions against the dispatchers' solutions. The comparison measures were the computation time and total delay. For benchmarking purposes, Artificial Neural Networks (ANNs) were developed to mimic the decision behavior of train dispatchers in actual train operations in Turkish State Railways. Louwerse and Huisman [26] focused on adjusting the timetable of a passenger railway operator in case of both partial and complete blockades of a railway line. Given a forecast of the characteristics of the disruption, the main objective was to maximize the service level offered to the passengers. They presented integer programming formulations and tested their models using instances from Netherlands Railways. Pellegrini et al. [27] proposed a mixed-integer linear programming formulation for tackling rescheduling problem, representing the infrastructure with fine granularity. They assessed the impact of this representation on the optimal solution by considering randomly-generated instances and multiple perturbation scenarios in France railways. Wang et al. [28] suggested two approaches to solve the optimal trajectory planning problem for multiple trains under both fixed and moving block signalling systems. They proposed a mixed integer linear programming problem with minimising energy consumption as the objective function considered. Veelenturf et al. [29] focused on timetable rescheduling for passenger trains. They formulated an integer programming model, which minimizes the number of cancelled and delayed trains while adhering to infrastructure and rolling stock capacity constraints. The possibility of rerouting trains in order to reduce the number of cancelled and delayed trains is also considered. Kang et al. [30] proposed a GA-based rescheduling model for last trains with the consideration of train delays caused by incidents that occurred in train operations. They tried to minimize the running time and the dwell time to maximize the average network accessibility. The case study of Beijing railway transit network shows that once a delay occurs in a section, the most effective way to adjust the time table consists of adjusting the running time of trains that have strong transfer relationships with the delay section. Zhan et al. [31] proposed a mixed-integer linear programming formulation that considers delaying and cancellation strategies and station capacity. Their goal 
is to minimize the number of canceled trains and the total weighted delay. The model is tested on real-world instances of the Beijing-Shanghai high-speed railway line. The results show that the model is promising for reducing the effect of a disruption on passenger service, especially in comparison with a heuristic method used in practice.

Most studies in train rescheduling have been carried out merely by applying delay strategy aimed at minimizing the average delays and total delays [9], but far too little attention has been paid to train cancelling strategy as well. The aim of this study is to present a novel approach to reschedule the trains which simultaneously incorporates three rescheduling policies: cancelling, delaying, and re-ordering trains. The special privilege of this approach is to restrict the incident effects to a predetermined time threshold. So, the approach is called "restriction rescheduling approach". Given the infrastructure situation, the characteristics of the incident as well as train delaying and cancellation costs, our goal is to determine a conflict-free timetable, specifying which trains will be cancelled and which ones will still be delayed after occurrence of the incident. To obtain the optimal solution, we have proposed a mixed-integer mathematical model, which respects all different constraints considered by the approach. The basic imperfection of this model is for the large-scale cases, in which finding an optimal solution may require an enormous amount of computation time due to the NP-hard nature. Hence, we have also proposed an innovative exact solution method based on Branch-and-Bound (B\&B) algorithm to solve the large-scale problems via the aforementioned approach. Furthermore, a heuristic beam search technique is developed in order to find near-optimal solutions in much shorter times.

The current article is organized as follows. In Section 2, the details of the proposed rescheduling approach are described. In Section 3, the mathematical model used to solve the problem is represented. The exact "Three-Phase Solution Method" and the heuristic beam search technique are completely elucidated in Section 4. In Section 5, the computational experiments from two real-world double-track railways are offered.
Finally, the concluding remarks are given at the end to summarize the contributions of this article.

\section{Description of the problem}

This study focuses on train rescheduling problem in the double-track railways. The studied degraded mode is the one in which an unforeseen incident occurs in one of the block sections and makes it out-of-service over a specific time horizon. The time of incident occurrence is called BOI (Beginning Of Incident) and the approximated end time of the incident is called EOI. It is a common practice for a central traffic control to approximate the time EOI based on the incident type and previous statistics. The incident may disrupt a major part of the primary timetable. Thus, the rescheduling must be quickly achieved aiming at restricting the delay propagations; since the less a part of the primary timetable is modified, the better the rescheduled timetable is $[6,32]$. To revive the primary timetable immediately after an occurrence of an incident, we have proposed "restriction rescheduling approach", which simultaneously applies cancelling, delaying, and reordering policies.

For more clarification, a simple example is employed. Figure 1(a) represents the primary scheduling graph of a hypothetical railway corridor that consists of four block sections (numbered B1 to B4) and four trains $\left(T_{1}\right.$ to $\left.T_{4}\right)$. The horizontal axis is time and the vertical one is block section. Each train is represented using a line (continuous and dotted, thick, and thin) where the start and the end of the line in each block section represent the departure and arrival times, respectively. The origin and the destination of all trains are B1 and B4, respectively. Now, suppose that an unforeseen incident occurs at the time BOI and makes B2 out-ofservice. The approximated time to reopen this block section is the time EOI. The incident time horizon is the difference between EOI and BOI. Therefore, no train can pass the incident block section (B2) during this horizon. As shown in Figure 1(b), $T_{1}$ and $T_{2}$ are directly delayed due to the incident; consequently, trains $T_{3}$ and $T_{4}$ are affected by the secondary delays. Then, all trains would be deviated from their primary schedules.

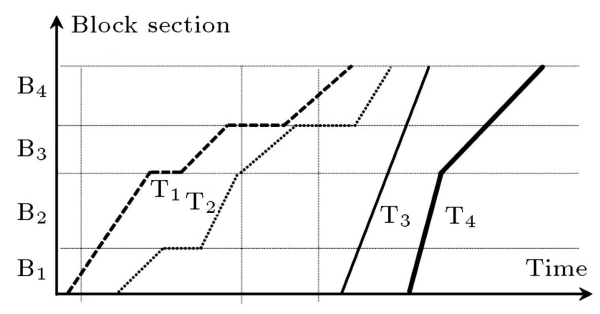

(a)

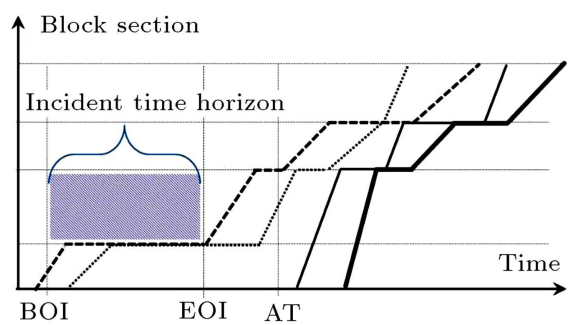

(b)

Figure 1. The train graphs before and after incident: (a) Primary graph, and (b) rescheduling graph. 


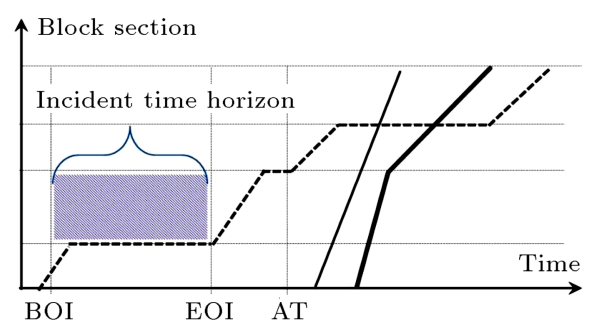

(a)

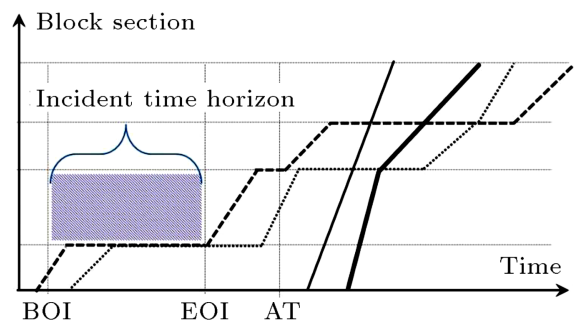

(b)

Figure 2. Rescheduling graph using "Restriction Rescheduling Approach": (a) Rescheduling with cancellation, and (b) rescheduling without cancellation.

The substantial advantage of this restriction is to prevent the delay propagation between specific amounts of trains. Such trains are called unchanged. These trains are not delayed, reordered, or cancelled due to the incident. For these trains, the departure time from the origin, specified in the primary timetable, is greater than Affecting Threshold (AT). In the rescheduling process, the schedules of such trains are guaranteed to remain unchanged, so that they travel exactly according to their primary schedules.All trains except the unchanged ones are considered as the rescheduled trains. It is worth mentioning that although this approach guarantees the punctual revival of the primary timetable, it limits the available time to replan the rescheduled trains which are affected by the incident. In other words, the unchanged trains impose extra restrictions on the rescheduled ones. Thus, some rescheduled trains may confront large delays, so that cancellation becomes more justifiable for them. Of course, it is not the case of all rescheduled ones, since the ones which started moving before BOI, are not capable of being cancelled. The cancellable trains are merely the rescheduled ones with origin departure time greater than BOI. According to Figure 2, $T_{1}$ and $T_{2}$ are rescheduled trains, $T_{3}$ and $T_{4}$ are unchanged ones, and $T_{2}$ is the only cancellable one. Sum of the deviation cost for $T_{1}$ and $T_{2}$ is called "Cost_a" and sum of cancellation cost of $T_{2}$ and deviation cost of $T_{1}$ after cancellation of $T_{2}$, is called "Cost_b". In the rescheduling process, if Cost_a is greater than Cost_b, then it is better to cancel $T_{2}$ (Figure 2(a)). Otherwise, no train is cancelled (Figure 2(b)).

To run the rescheduling process via the mentioned approach, the inputs of the problem include: incident identifiers (BOI, EOI, and incident block section), trains priorities, Affecting Threshold (AT), and cancellation and delay costs as well as the primary timetable.

In restriction rescheduling approach, the time duration affected by incident is restricted to "Affecting Threshold" (AT), which is one of the problem inputs selected by the central traffic control.

Based on AT, it would be determined for each train whether it is rescheduled or unchanged. The

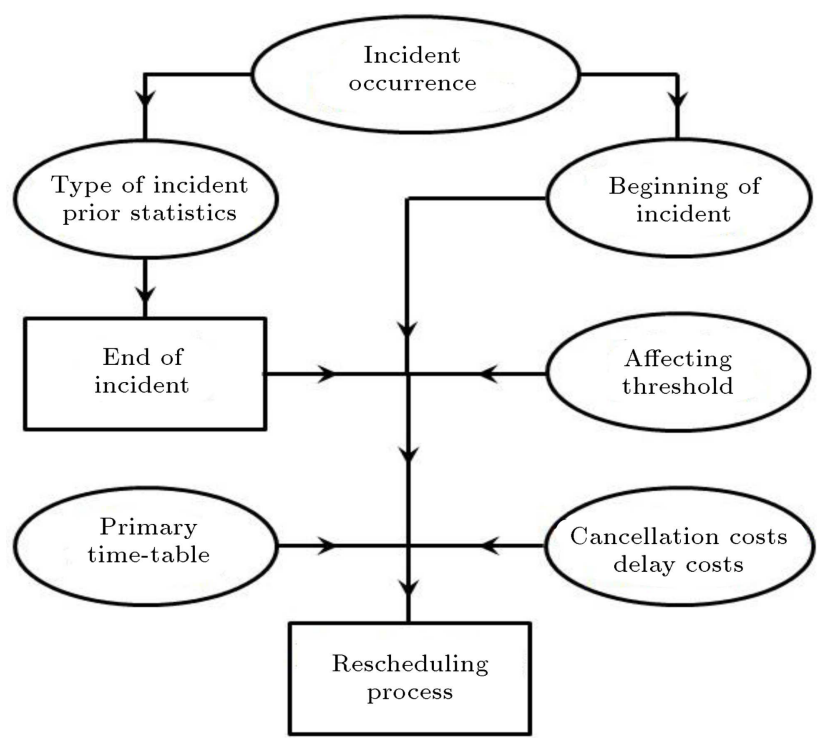

Figure 3. Flowchart of restriction rescheduling approach.

rescheduling process is executed merely for rescheduled trains. The flowchart of restriction rescheduling approach is illustrated in Figure 3.

Note that train cancellation is considered a policy sometimes used for incident conditions. Nonetheless, in most of the times, the major shortcoming is that the cancellation has merely been in the realm of human expertise, relying on train dispatcher's intuitive knowledge, experience, and judgment. Then, the solutions found by dispatchers may not necessarily be optimal or even near-optimal from efficiency standpoint, especially for the medium and large-scale problems.

The main objective of this article is to provide solutions which allow railway operators to optimize the rescheduling process through restriction rescheduling approach. More specifically, we try to optimally tackle the problems by reducing the total solving time, which is much important, especially at incident conditions.

\section{Rescheduling optimization model}

To find a new conflict-free timetable compatible with the restriction rescheduling approach aiming at guar- 
anteeing the optimal solution, a mixed-integer optimization model is developed in this section. The model simultaneously incorporates three rescheduling policies: cancelling, delaying, and re-ordering trains.

\subsection{Definitions}

The sets, parameters, and variables used in the model as well as other symbols used in this article are represented in Table 1.

Table 1. List of employed symbols.

\begin{tabular}{|c|c|c|c|}
\hline Symbol & Definition & Symbol & Definition \\
\hline$X_{i, b}$ & $\begin{array}{l}\text { (Continuous variable) Arrival time of } \\
\text { train } i \text { to the end of block section } b\end{array}$ & $\mathrm{AT}$ & Affecting threshold \\
\hline$Y_{i, b}$ & $\begin{array}{l}\text { (Continuous variable) Departure time of } \\
\text { train } i \text { from the beginning of block section } b\end{array}$ & $\hat{b}$ & Incident block section \\
\hline$Z_{i}$ & $\begin{array}{l}\text { (Binary variable) Equals } 1 \text { if train } i \\
\text { is cancelled and } 0 \text { otherwise }\end{array}$ & $H_{i j b}$ & $\begin{array}{l}\text { Minimum headway between leading train } j \\
\text { and the following train } i \text { at block section } b\end{array}$ \\
\hline$A_{i j b}$ & $\begin{array}{l}\text { (Binary variable) Equals } 1 \text { if train } i \text { traverses } \\
\text { block section } b \text { before train } j \text { and } 0 \text { otherwise }\end{array}$ & $S T_{i, b}$ & $\begin{array}{l}\text { Minimum required stopping time of train } i \\
\text { in station located at end of block section } b\end{array}$ \\
\hline$\theta_{i j b}$ & $\begin{array}{l}\text { (Binary variable) Train position variable to } \\
\text { avoid conflict with unchanged trains }\end{array}$ & $t_{i, b}$ & $\begin{array}{l}\text { The time required for train } i \text { to pass } \\
\text { through block section } b\end{array}$ \\
\hline$B$ & Set of the block sections of the railway & $\hat{X}_{i, b}$ & $\begin{array}{l}\text { Arrival time of train } i \text { to end of block } \\
\text { section } b \text { in primary timetable }\end{array}$ \\
\hline$N$ & Set of all trains & $\hat{Y}_{i, b}$ & $\begin{array}{l}\text { Departure time of train } i \text { from beginning of } \\
\text { block section } b \text { in primary timetable }\end{array}$ \\
\hline$R$ & Set of the rescheduled trains & ANL & Active Node List \\
\hline$R^{\prime}$ & Set of the unchanged trains & $X_{i, b}^{\lambda}$ & $\begin{array}{l}\text { Arrival time of train } i \text { to the end of } \\
\text { block section } b \text { at node } \lambda\end{array}$ \\
\hline$B_{i}$ & $\begin{array}{l}\text { Set of block sections which must be } \\
\text { passed by train } i\end{array}$ & $Y_{i, b}^{\lambda}$ & $\begin{array}{l}\text { Departure time of train } i \text { from start } \\
\text { of block section } b \text { at node } \lambda\end{array}$ \\
\hline$D_{i}$ & $\begin{array}{l}\text { Total cost of deviation from } \\
\text { primary schedule for train } i\end{array}$ & $M$ & A large positive number \\
\hline$b o_{i}$ & Origin block section of train $i$ & $t_{i b}$ & Travelling time of block section $b$ by train $i$ \\
\hline$b d_{i}$ & Destination block section of train $i$ & $\mathrm{LB}^{\lambda}$ & The lower bound at node $\lambda$ \\
\hline$E_{T} O_{i}$ & $\begin{array}{l}\text { Earliest allowable time of train } i \\
\text { to depart from its origin }\end{array}$ & $\Delta^{\lambda}$ & $\begin{array}{l}\text { Set of the non-scheduled train- } \\
\text { block sections at node } \lambda\end{array}$ \\
\hline$C C_{i}$ & Cancellation cost of train $i$ & $l a_{b}^{\lambda}$ & $\begin{array}{l}\text { Arrival time associated with last train } \\
\text { that passes } b \text { at node } \lambda\end{array}$ \\
\hline$C D_{i}$ & Cost of 1-minute delay of train $i$ & $\mathrm{MA}^{\lambda}$ & $\begin{array}{l}\text { The minimum arrival times of trains belong } \\
\text { to } \Delta_{\lambda} \text { at node } \lambda\end{array}$ \\
\hline BOI & Beginning of the incident time horizon & UB & The Upper Bound \\
\hline EOI & End of the incident time horizon & $\mathrm{AT}$ & Affecting Threshold \\
\hline
\end{tabular}




\subsection{Mathematical formulation}

$$
\begin{aligned}
& \operatorname{Min} z=\sum_{i \in R} D_{i}+\sum_{i \in R}\left(C C_{i} \times Z_{i}\right), \\
& D_{i} \leq M \times\left(1-Z_{i}\right) \quad \forall i \in R \\
& D_{i} \leq C D_{i} \times\left(X_{i, b}-\hat{X}_{i, b}\right)+M \times Z_{i},
\end{aligned}
$$$$
\forall i \in R, \quad \forall b \in B_{i}-\left\{b d_{i}\right\}
$$

$D_{i} \geq C D_{i} \times\left(X_{i, b}-\hat{X}_{i, b}\right)-M \times Z_{i}$

$\forall i \in R, \quad \forall b \in B_{i}-\left\{b d_{i}\right\}$

$Y_{i, b} \leq M \times\left(1-Z_{i}\right) \quad \forall i \in R, \quad \forall b \in B_{i}$

$X_{i, b} \leq M \times\left(1-Z_{i}\right) \quad \forall i \in R, \quad \forall b \in B_{i}$,

$Y_{i, b o_{i}} \geq E T O_{i}-M \times Z_{i} \quad \forall i \in R$

$$
S T_{i, b}-M \times Z_{i} \leq Y_{i,(b+1)}-X_{i, b}
$$

$\forall i \in R, \quad \forall b \in B_{i}-\left\{b d_{i}\right\}$

$X_{i, b}-Y_{i, b}=t_{i, b} \times\left(1-Z_{i}\right)$

$\forall i \in R, \quad \forall b \in B_{i}$,

$Y_{i, b} \geq X_{i,(b-1)}$

$\forall i \in R, \quad \forall b \in B_{i}, \quad b \geq b o_{i}+1$,

$Y_{j, b}+M \times\left(1+Z_{i}+Z_{j}-A_{i j b}\right) \geq X_{i, b}+H_{i j b}$

$$
\forall i, j \in R, \quad \forall b \in B_{i}, \quad i \neq j
$$

$Y_{i, b}+M \times\left(Z_{i}+Z_{j}+A_{i j b}\right) \geq X_{j, b}+H_{i j b}$

$$
\forall i, j \in R, \quad \forall b \in B_{i}, \quad i \neq j
$$

$$
Y_{i, \hat{b}}>E O I-M \times Z_{i} \quad \forall i \in R
$$

$$
X_{i, b}-M \times\left(1+Z_{i}-\theta_{i j b}\right) \leq \hat{Y}_{j, b}
$$

$\forall i \in R, \quad \forall j \in R^{\prime}, \quad \forall b \in B_{i}$,

$$
\begin{aligned}
& Y_{i, b}+M \times\left(Z_{i}+\theta_{i j b}\right)>\hat{X}_{j, b} \\
& \forall i \in R, \quad \forall j \in R^{\prime}, \quad \forall b \in B_{i} .
\end{aligned}
$$

The objective function of the optimization model is to minimize the cost and consists of two cost parts: The former part is devoted to cost of deviation from the primary timetable, and the second part is for the cost of train cancellation, as formulated in Eq. (1).

Constraints (2) to (4) represent the cost of deviation from the primary timetable. According to Constraints (2), if train $i$ is cancelled $\left(Z_{i}=1\right)$, the deviation cost is zero for this train. Otherwise $\left(Z_{i}=0\right)$, Constraints (3) and (4) would be active, so that the deviation cost for train $i, D_{i}$ equals the product of: the cost of 1-minute delay of train $i, C D_{i}$ and the difference between arrival times to the destination, in primary and rescheduling plans. It is mentioned that for non-cancellable trains, the cancellation binary variable $(Z)$ must be set to the value of zero. By applying Constraints (5) and (6), the departure/arrival times of the cancelled trains in all block sections change to zero. Constraints (7) to (13) are active for all un-cancelled trains: Constraint (7) ensures that the departure time of each train from its origin is not less than the earliest allowable time. Constraints (8) guarantee that the stopping time of trains at each station is greater than, or equal to, the corresponding minimum required stopping times. Constraints (9) determine the time length required for each train to pass a block section. Constraints (10) are specialized for the movement continuity of trains. It guarantees that the departure time of train $i$ from start of block section $b$ is greater than, or equal to, the arrival time of that train to end of the previous block section $(b-1)$. The constraints ensure that the trains pass the block sections one after another. Constrains (11) and (12) guarantee no coincidence of the trains. If $A_{i j b}$ equals 1 (train $i$ enters block section $b$ before train $j$ ), Constraints (11) would be active. Otherwise, Constraints (12) would be active. So, the train re-ordering in all block sections is possible by applying Constraints (11) and (12).

Constraints (13) inhibit any movements of the trains through the incident block section during the incident time horizon. By this constraint, the departure time of trains from start of the incident block section is postponed to a time after EOI.

Constraints (14) and (15) are used to avoid any conflict with unchanged trains whose departure/arrival times in the block sections are considered as the constraints for rescheduled trains. In Constraints (14) and (15), binary decision variable, $\theta_{i j b}$, is 1 if $Y_{i, b} \leq \hat{Y}_{j, b}, i \in$ $R, j \in R^{\prime}$, and 0 if otherwise. According to Constraints (14), if $\theta_{i j b}$ equals 1 , then the arrival time of train $i$ is less than the departure time of unchanged train $j$. According to Constraints (15), if $\theta_{i j b}$ equals 0 , then the departure time of train $i$ is greater than the arrival time of unchanged train $j$. If train $i$ is cancelled, $Z_{i}=1$, both Constraints (14) and (15) are inactive [33,34].

\section{Three-phase solution method}

Although it is possible to find the optimal solution of a 
problem via the optimization model, it may require an enormous amount of solving time with the increasing problem size due to the NP-hard nature [35,36]. To overcome this drawback, we have developed "ThreePhase Solution Method". The specific distinction of this method is to provide the optimal solution of the main rescheduling problem in much shorter time compared to the time taken by CPLEX software to solve MIP model described in Section 3. The method is composed of three phases, each of which is executed by an innovative algorithm. In Phase I, the problem is considered with the assumption of no train cancellation. To solve this problem, a "Branch and Bound" (B\&B) algorithm is proposed. The results achieved from Phase I are considered as the inputs for Phase II. The substantial goal of Phase II is to reach an appropriate upper bound for the main problem with a short computing time. In this phase, all different combinations of the cancellable trains are surveyed and corresponded to each one, a sub-problem is created. The sub-problems are solved using "Local Left Shifting" (LLS) algorithm, which is proposed and discussed in Subsection 4.2. The basic assumption of this algorithm is to fix the order of the trains. In Phase III, each of the sub-problems produced in previous phase is solved by B\&B algorithm. The upper bound found by Phase II is used in Phase III to provide an initial incumbent solution. The output of Phase III is the optimal solution of the main problem.

\subsection{Phase I: B\&B algorithm with no train cancellation}

In Phase I of the solution method, it is assumed that no rescheduled train is cancelled. Thus, the main function expected to be performed in this phase is to provide the optimal rescheduling timetable for all rescheduled trains, so that all of the constraints related to "restriction rescheduling approach" (including general constraints and special constraints for no-coincidence with unchanged trains) are satisfied. To do this, we have used B\&B algorithm. The proposed algorithm generates all the feasible schedules. Each node, e.g., $\lambda$, of the branching tree corresponds with a partial schedule. The lower bound of node $\lambda, L B_{\lambda}$, is the total cost of arrival-time deviations from the primary timetable. If in any steps of the $\mathrm{B} \& \mathrm{~B}$ algorithm, all rescheduled trains are planned in $\lambda$, then node $\lambda$ is at the bottom of the tree and represents a complete feasible schedule that can no longer be branched. Moreover, an Active Node List (ANL) contains the nodes that have the possibility of branching. This list is updated in each step of the algorithm, so that the ANL is descending based on the number of non-rescheduled train-block sections of the nodes. Whenever this list is empty, the algorithm is terminated. The proposed $\mathrm{B} \& \mathrm{~B}$ algorithm for Phase $\mathrm{I}$ of the solution method is given as follows:
- Step 1: Initial condition. Consider initial node $\lambda$ as the first train which could start not later than others:

$$
\begin{aligned}
& \mathrm{ANL} \leftarrow \text { Initial node } \lambda, \quad \Delta_{\lambda} \leftarrow\left\{\left(i, b o_{i}\right) \forall i \in R\right\}, \\
& Y_{i, b o_{i}}^{\lambda} \leftarrow E T O_{i} \quad \forall i \in R, \quad l a_{b}^{\lambda} \leftarrow 0, \quad \forall b \in B, \\
& \mathrm{UB} \leftarrow \infty
\end{aligned}
$$

- Step 2: Block section selection:

$$
\begin{aligned}
& X_{i, b}^{\lambda} \leftarrow Y_{i, b}^{\lambda}+t_{i, b} \quad \forall(i, b) \in \Delta_{\lambda}, \\
& M A^{\lambda} \leftarrow \operatorname{Min}\left\{X_{i, b}^{\lambda} \mid(i, b) \in \Delta_{\lambda}\right\} \\
& b^{*} \leftarrow \text { The block section related to } M A^{\lambda}, \\
& X_{i, b}^{\lambda} \leftarrow 0 \quad \forall(i, b) \in \Delta_{\lambda}
\end{aligned}
$$

- Step 3: Branching:

$$
\Delta_{\lambda}^{\prime} \leftarrow\left\{\left(i, b^{*}\right) \in \Delta_{\lambda} \mid Y_{i, b^{*}}^{\lambda}<M A^{\lambda}\right\} .
$$

For each member of $\Delta_{\lambda}^{\prime}$, generate a new node beneath node $\lambda$. For each new node, $\lambda^{\prime}$, transfer all data that exist in node $\lambda$ to node $\lambda^{\prime}$.

Furthermore, consider the following alterations (note: $i^{*}$ is the selected train correspondence with the node $\lambda^{\prime}$ ):

$$
\begin{aligned}
& X_{i^{*}, b^{*}}^{\lambda^{\prime}} \leftarrow Y_{i^{*}, b^{*}}^{\lambda^{\prime}}+t_{i^{*}, b^{*}}, \\
& l a_{b^{*}}^{\lambda^{\prime}} \leftarrow X_{i^{*}, b^{*}}^{\lambda^{\prime}}+H_{\min }, \\
& X_{i, b^{*}}^{\lambda^{\prime}} \leftarrow l a_{b^{*}}^{\lambda^{\prime}} \quad \forall\left(i, b^{*}\right) \in \Delta_{\lambda}^{\prime}-\left\{\left(i^{*}, j^{*}\right)\right\}, \\
& Y_{i^{*}, b^{\prime}}^{\lambda^{\prime}} \leftarrow X_{i^{*}, b^{*}}^{\lambda^{\prime}}+S T_{i^{*} b^{*}},
\end{aligned}
$$

where $b^{\prime}$ is the next block section that should be met by train $i^{*}$ after $b^{*}$ and $H_{\min }$ is the minimum headway required between two consecutive trains.

Note that the following relation to inhibit any train movement in incident block section during incident time horizon:

$$
\text { If } Y_{i^{*}, \hat{b}}^{\lambda^{\prime}}<E O I \text { then } Y_{i^{*}, b^{\prime}}^{\lambda^{\prime}} \leftarrow E O I .
$$

Also, consider the following expressions for nocoincidence with unchanged trains:

$$
\text { If } Y_{i^{*}, b^{*}}^{\lambda^{\prime}}<Y_{j, b^{*}}^{\lambda^{\prime}} \text { and } X_{i^{*}, b^{*}}^{\lambda^{\prime}}>Y_{j, b^{*}}^{\lambda^{\prime}}-H_{\min }
$$

then:

$$
\begin{aligned}
& Y_{i^{*}, b^{*}}^{\lambda^{\prime}} \leftarrow X_{j, b^{*}}^{\lambda^{\prime}}+H_{\min }, \forall j \in R^{\prime} . \\
& \text { If } Y_{i^{*}, b^{*}}^{\lambda^{\prime}}>Y_{j, b^{*}}^{\lambda^{\prime}} \text { and } Y_{i^{*}, b^{*}}^{\lambda^{\prime}}<X_{j, b^{*}}^{\lambda^{\prime}}+H_{\min },
\end{aligned}
$$


then:

$$
\begin{aligned}
& Y_{i^{*}, b^{*}}^{\lambda^{\prime}} \leftarrow X_{j, b^{*}}^{\lambda^{\prime}}+H_{\min }, \forall j \in R^{\prime}, \\
& \Delta_{\lambda^{\prime}} \leftarrow\left\{\Delta_{\lambda} \cup\left(i^{*}, j^{\prime}\right)\right\}-\left(i^{*}, j^{*}\right) .
\end{aligned}
$$

Compute the Lower Bound (LB) by adding cost of arrival-time deviations from the primary timetable for:

$$
i^{*}: L B^{\lambda^{\prime}} \leftarrow \mathrm{LB}^{\lambda}+C D_{i^{*}} \times\left(X_{i^{*}, b^{*}}^{\lambda^{\prime}}-\hat{X}_{i^{*}, b^{*}}^{\lambda^{\prime}}\right)
$$

- Step 4: Fathoming nodes. Fathom the new node $\lambda^{\prime}$, if the LB of the node is greater than, or equal to, the $\mathrm{UB}_{1}$. Update the ANL.

- Step 5: Node selection. If $\Delta_{\lambda}^{\prime}$ is empty (i.e. a new schedule is achieved), update $\mathrm{UB}_{1}$ if it is necessary. If ANL is empty, then the algorithm is terminated, return the best-found timetable; otherwise, select the first active nodes from the ANL. If $\Delta_{\lambda}^{\prime}$ is not empty, select a node beneath node $\lambda$ based on the first-in-first-served rule and transfer other such nodes to the ANL. Update the ANL. Go to Step 2.

\subsection{Phase II: Upper bound generation}

Phase II of the solution method represents a heuristic algorithm to find a suitable upper bound for the main problem in a short computing time. In this phase, we have proposed Local Left Shifting (LLS) algorithm. The basic assumption of this algorithm is to fix the order of the trains. For obvious elucidation of the procedure executed by this algorithm, a simple instance, with three trains (numbered $T_{1}, T_{2}$, and $T_{3}$ ) and four block sections, is employed. As shown in Figure 4(a), the trains are planned one after another, so that each block section is occupied by at most one train at a time. Now, suppose that $T_{2}$ is cancelled. For each block section, the train(s) departed after $T_{2}$ (e.g., $T_{3}$ ) would encounter a released space due to this cancellation. Therefore, $T_{3}$ is allowed to locally shift towards left as far as possible (Figure 4(b)). It reduces the delay values, and consequently results in less deviation from the primary timetable. It is clear that the trains departed before the cancelled train are not shifted at all (e.g., $T_{1}$ ).

It is also worth mentioning that the left-shifting must be separately executed for each block section (local shifting). That is why the value of shifting is not necessarily the same in different block sections.

For the cases in which more than one train is cancelled, local left shifting in a block section must be executed merely for non-cancelled trains departed after the firstly-departed cancelled train. LLS algorithm is described as follows:

For each block section $(b)$ :

\{

Sort both rescheduled and unchanged trains based on their departure times, from the timetable obtained in Phase I.

Set last planned time of the block section (LA $(b))$ equal to zero.

Specify the firstly-departed cancelled rescheduled train $\left(i^{*}\right)$.

Set both arrival and departure times of the cancelled rescheduled train(s) equal to zero.

For each non-cancelled rescheduled train $(i)$ departed after $i^{*}$ :

\{

Set LA $(b)$ equal to the arrival time of the previouslydeparted rescheduled train $(i-1)$.

Specify minimum departure time of train $i$ (MD $(i, b))$ regarding both the minimum required stopping time in prior station and the departure time of train $i$ in the primary timetable.

Set departure time of train $i$ equals to: maximum [LA $(b), \operatorname{MD}(i, b)]$.

For each unchanged train $(j)$ :

\{

Check the possible conflict between trains $i$ and $j$.

Update departure time of train $i$, if necessary.

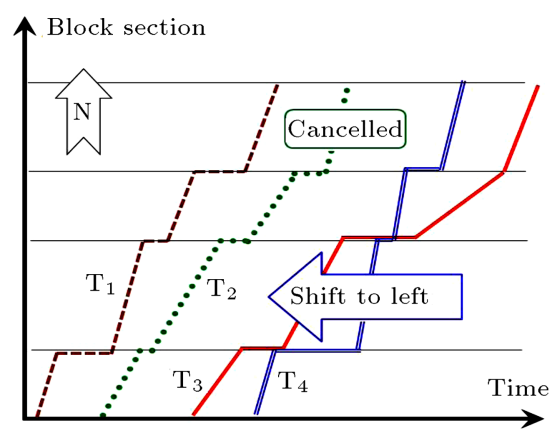

(a)

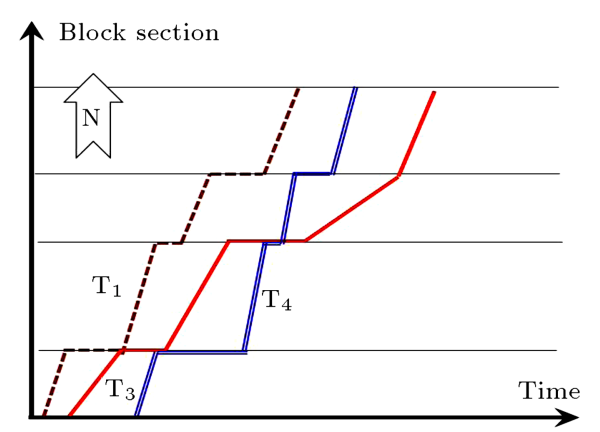

(b)

Figure 4. Schematic sketch of procedure executed by LLS algorithm: (a) Before cancellation of $T_{2}$, and (b) after cancellation of $T_{2}$. 


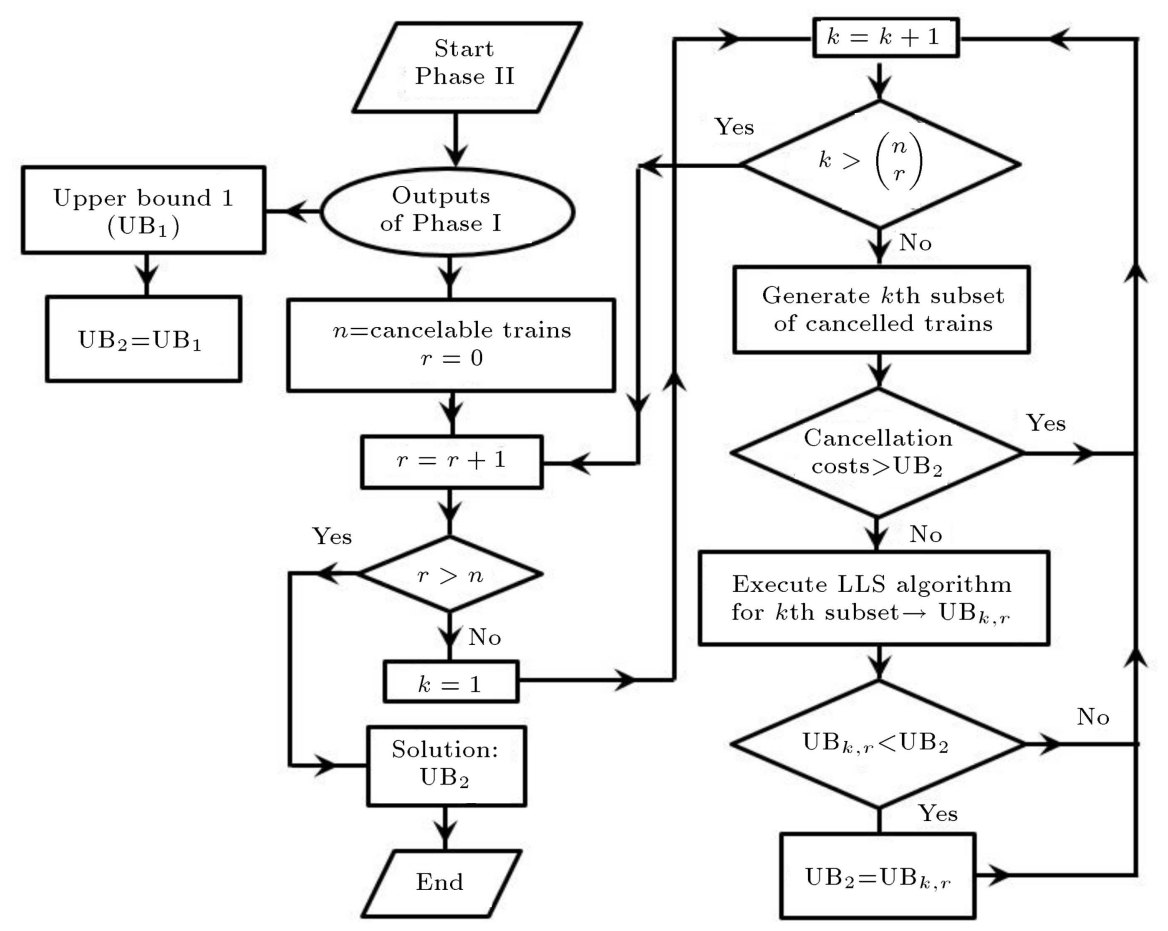

Figure 5. Flowchart of the methodology applied in Phase II.

\}

Update LA $(b)$.

Set arrival time of $i$ equal to sum of [departure time of train $i$, time of passing train $i$ through block section $b]$.

$$
\}
$$$$
\}
$$

It is clear that all rescheduled trains are not necessarily possible to be cancelled. The cancellable trains are merely the rescheduled ones in which the departure time from the primary origin is greater than the Beginning time Of Incident (BOI). In other words, at the time the incident occurs, the cancellable trains have not departed from the origin. Now, suppose that there are $n$ cancellable trains $(n>0)$. Number of entire combinations of $n$ cancellable trains is:

$$
\begin{aligned}
\left(\begin{array}{l}
n \\
1
\end{array}\right) & +\left(\begin{array}{l}
n \\
2
\end{array}\right)+\left(\begin{array}{l}
n \\
3
\end{array}\right)+\ldots+\left(\begin{array}{l}
n \\
n
\end{array}\right)=\sum_{r=1}^{n} \frac{n !}{r !(n-r) !} \\
& =2^{n}-1 .
\end{aligned}
$$

Corresponding to each combination, there is one subproblem named in this article as: "combinatorial subproblem". In other words, there are $\frac{n !}{r !(n-r) !}$ combinatorial sub-problems, each of which contains $r$ cancelled trains. Each of these sub-problems is solved by LLS algorithm. If the upper bound, $\mathrm{UB}_{2}$, achieved after solving a combinatorial sub-problem is less than incumbent (best so-far solution achieved), $\mathrm{UB}_{2}$ will be updated. Meanwhile, if the cancellation cost of a subproblem exceeds the incumbent, then this sub-problem can be fathomed and there is no need to execute LLS algorithm for that one. Therefore, in Phase II, we must solve at most $2^{n}-1$ combinatorial problems. In Figure 5, the flowchart of the methodology applied in Phase II is illustrated.

\subsection{Phase III: B\&B algorithm for all cancellation combinations}

Since the LLS algorithm does not consider the changes in train orders, the graph obtained for each combinatorial sub-problem from Phase II is not necessarily optimal. In Phase III, each combinatorial sub-problem is solved by $\mathrm{B} \& \mathrm{~B}$ algorithm to obtain the optimal solution. The lower bound of the nodes consists of two cost parts: the cost of deviation from the primary timetable and the cost of train cancellation. However, if the cancellation cost of a sub-problem exceeds the incumbent, there is no need to execute B\&B algorithm for that one. Therefore, in Phase III, we must solve at most $2^{n}-1$ combinatorial problems. The upper bound found by Phase II $\left(\mathrm{UB}_{2}\right)$ is used in Phase III to provide an appropriate initial incumbent solution.

The steps of B\&B algorithm used in Phase III is similar to the ones described for Phase I; therefore, it is not repeated here. The output of Phase III $\left(\mathrm{UB}_{3}\right)$ is the optimal solution of the main rescheduling problem.

\subsection{Heuristic beam search technique}

As outlined, the proposed "Three-Phase Solution Method" is based on B\&B algorithm, which generates the optimal solution. However, the optimal solution 
is unattainable in a reasonable time for real largescale problems due to the NP-hard nature of the train-timetabling problem [37]. In some cases, it is impractical to generate optimal solutions within a given (usually small) time bound [38]. Moreover, optimal solutions are not required usually in rescheduling problems. Since, for such problems, achieving a non-optimal suitable solution in a short time has more significance than finding the optimal solution. Consequently, a trade-off between optimality and solving time must be considered. According to Jafari and Zegordi [39], rescheduling solutions need to be generated in less than 3 minutes. D'Ariano [38] recommended a value of 10 minutes as a tolerable time bound for a train rescheduling problem. Consequently, in real-life situations, rescheduling must be performed in a restricted period of time.

To find a near-optimum solution for large-scale problems in a limited amount of time compatible with the real-time use, we have used two beam search techniques in this section. The first one (B.S.T.1) is developed by Shafia et al. [29], whereas the latter (B.S.T.2) is the heuristic one, proposed in this work.

B.S.T.1: In this technique, a fathoming rule is used. According to this rule, for each problem, if the lower bound of node $\lambda, L B^{\lambda}$, exceeds a specific percentage of the upper bound, UB, then the node must be fathomed. In other words, if the following inequality is satisfied, node $\lambda$ must be fathomed:

$$
\mathrm{LB}^{\lambda}>\left(1-f_{1} \times \frac{\mathrm{TB}-\mathrm{TB}^{\lambda}}{\mathrm{TB}}\right) \times \mathrm{UB},
$$

where TB is the number of train-block sections of the problem and $\mathrm{TB}^{\lambda}$ is the number of the scheduled trainblock sections at node $\lambda$. The value of parameter $f_{1}$ addresses the trade-off between objective function value and the required running time to achieve the final solution.

B.S.T.2: For a real large-scale problem, the size of branch and bound tree is likely to be so large that an "out of memory" error happens due to memory shortage for storing all nodes generated. The main idea in our heuristic beam search technique is to limit growing of the whole tree as much as possible. This technique simultaneously applies two fathoming rules: the first rule is exactly similar to the one used in B.S.T.1. The second rule represents that for each problem, the length of the Active Node List (ANL) must be restricted to a threshold value. Such a restriction continuously control the length of ANL. Then, some nodes may not be allowed to add ANL, when the number of existing nodes equals the threshold value. In other words, in each moment, the number of active nodes in the list is at most equal to the threshold value. This value is a function of both block sections and rescheduled trains. After examining different large-scale problems, the following equation is proposed for the threshold value:

$$
\text { Threshold value }=f_{2} \times(\mathrm{NB} \times \mathrm{NT}) \text {, }
$$

where $f_{2}$ is a coefficient, NB and NT are the number of the block sections and number of the rescheduled trains, respectively.

\section{Computational experiments: Results and discussions}

To assess validation of the proposed exact solution method and the heuristic beam search technique, several computational experiments are carried out on two double-track railway corridors of Iran network: BafghSirjan and Tehran-Mashhad railways. The first one is around $253 \mathrm{~km}$ long which consists of 10 block sections and services both freight and passenger trains. The latter one is the longest Iranian double-track railway with $924 \mathrm{~km}$ long dedicated to four types of passenger trains and consists of 49 block sections. To reschedule the problems via restriction rescheduling approach, both mathematical model and the proposed solution method were implemented in JAVA language and executed on a PC equipped with a $\mathrm{CPU}$ at $2.66 \mathrm{GHz}, 4$ GB RAM and windows 7 operating system. The model was solved by CPLEX 11 software which automatically generates optimal solutions.

We have solved several experimental examples, considering different values of "Cost Ratio" and "Effect Ratio". Cost Ratio of train $i$ is defined as the ratio of cancellation cost of train $i$ to cost of 1-minute delay of that train: $\mathrm{CR}_{i}=\frac{\mathrm{CC}_{i}}{\mathrm{CD}_{i}}$. Effect Ratio is the proportion of the duration affected by incident to the incident time horizon: $\mathrm{ER}=\frac{\mathrm{AT}-\mathrm{BOI}}{\mathrm{EOI}-\mathrm{BOI}}$. For each train, origin, destination, priority value, earliest allowable time to depart from origin, minimum stopping times, travel times, cancellation, and delay costs are considered as the inputs. Section 5.1 presents the results of the experimental examples to evaluate three-phase solution method. Section 5.2 reports the results of the examples to compare the performance of the proposed exact method with the heuristic algorithm.

\subsection{Evaluation of three-phase solution method}

Table 2 shows the results of the experimental problems in Bafgh-Sirjan railway corridor. Each problem represents a scenario with specific characteristics like incident properties, cost ratio, and effect ratio.

Some of the conclusions found by Table 2 are listed below: 
Table 2. The results of experimental problems in Bafgh-Sirjan railway corridor.

\begin{tabular}{|c|c|c|c|c|c|c|c|c|c|c|c|c|c|c|}
\hline \multicolumn{3}{|c|}{ Problems } & Ex.* 1 & Ex. & 2 Ex. 3 & 3 Ex. 4 & 4 Ex. 5 & 5 Ex. 6 & 6 Ex. 7 & 7 Ex. 8 & 8 Ex. 9 & Ex. 10 & Ex. 11 & Ex. 12 \\
\hline \multicolumn{3}{|c|}{ Num. of block sections } & 10 & 10 & 10 & 10 & 10 & 10 & 10 & 10 & 10 & 10 & 10 & 10 \\
\hline \multicolumn{3}{|c|}{ Num. of trains } & 15 & 15 & 15 & 15 & 15 & 15 & 15 & 15 & 15 & 15 & 15 & 15 \\
\hline \multicolumn{3}{|c|}{ BOI (min) } & 550 & 550 & 550 & 550 & 550 & 550 & 600 & 600 & 600 & 600 & 600 & 600 \\
\hline \multirow{2}{*}{\multicolumn{3}{|c|}{ EOI (min) }} & 650 & 650 & 650 & 650 & 650 & 650 & 800 & 800 & 800 & 800 & 800 & 800 \\
\hline & & & $\hat{b} \# 4$ & $\# 4$ & $\# 4$ & $\# 4$ & $\# 4$ & \# 4 & $\# 5$ & $\# 5$ & $\# 5$ & $\# 5$ & $\# 5$ & $\# 5$ \\
\hline \multicolumn{3}{|c|}{ Cost Ratio (CR) } & 500 & 2000 & 500 & 2000 & 500 & 2000 & 500 & 2000 & 500 & 2000 & 500 & 2000 \\
\hline \multicolumn{3}{|c|}{ Effect Ratio (ER) } & 0.5 & 0.5 & 1 & 1 & 1.5 & 1.5 & 0.5 & 0.5 & 1 & 1 & 1.5 & 1.5 \\
\hline \multicolumn{3}{|c|}{ Num. rescheduled trains } & 6 & 6 & 8 & 8 & 9 & 9 & 9 & 9 & 12 & 12 & 15 & 15 \\
\hline \multicolumn{3}{|c|}{ Num. cancelled trains } & 1 & 0 & 2 & 0 & 2 & 0 & 3 & 2 & 5 & 0 & 5 & 0 \\
\hline \multirow{2}{*}{ 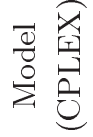 } & T.R.C ${ }^{* *}$ & & 4707 & 6063 & 3664 & 5911 & 3664 & 5824 & 8383 & \multirow{2}{*}{$* * *$} & \multirow{2}{*}{$* * *$} & \multirow{2}{*}{$* * *$} & \multirow{2}{*}{$* * *$} & \multirow{2}{*}{$* * *$} \\
\hline & $\begin{array}{c}\text { Total solvin } \\
\text { time ( } \mathrm{sec})\end{array}$ & & 9.4 & 27 & 57 & 649 & 114 & 4928 & 12.3 & & & & & \\
\hline \multirow{8}{*}{ 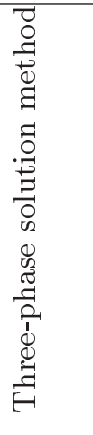 } & T.R.C C* $^{* *}$ & & 4707 & 6063 & 3664 & 5911 & 3664 & 5824 & 8383 & 15524 & $4 \quad 7847$ & 12535 & 7847 & 12473 \\
\hline & $\begin{array}{c}\text { Total solvin } \\
\text { time (sec) }\end{array}$ & & 0.02 & 0.03 & 0.06 & 0.05 & 0.11 & 0.11 & 0.08 & 0.11 & 0.36 & 0.3 & 86 & 92 \\
\hline & \multirow{3}{*}{ 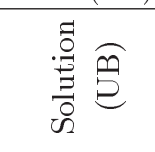 } & Phase I & 6063 & 6063 & 5911 & 5911 & 5824 & 5824 & 16738 & 16738 & 3 12535 & 12535 & 12473 & 12473 \\
\hline & & Phase II & 4707 & 6063 & 3664 & 5911 & 3719 & 5824 & 8383 & 15524 & 8386 & 12535 & 8535 & 12473 \\
\hline & & Phase III & 4707 & 6063 & 3664 & 5911 & 3664 & 5824 & 8383 & 15524 & 7847 & 12535 & 7847 & 12473 \\
\hline & \multirow{3}{*}{ 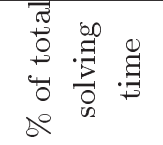 } & Phase I & $6 \%$ & $91 \%$ & $53 \%$ & $66 \%$ & $57 \%$ & $57 \%$ & $79 \%$ & $57 \%$ & $35 \%$ & $37 \%$ & $94 \%$ & $85 \%$ \\
\hline & & Phase II & $0 \%$ & $0 \%$ & $0 \%$ & $0 \%$ & $0 \%$ & $0 \%$ & $0 \%$ & $0 \%$ & $0 \%$ & $5 \%$ & $0 \%$ & $0 \%$ \\
\hline & & Phase III & $94 \%$ & $9 \%$ & $47 \%$ & $34 \%$ & $43 \%$ & $43 \%$ & $21 \%$ & $43 \%$ & $65 \%$ & $58 \%$ & $6 \%$ & $15 \%$ \\
\hline
\end{tabular}

*Ex.: Example; **T.R.C: Total Rescheduling Cost (monetary units);

*** Not found optimal solution via CPLEX after 3 hours.

a) The proposed method is capable of finding the optimal solution much faster than CPLEX 11 software package in all solved problems. The larger the scale of the problem, the more highlighted the importance of such time reduction. For any one of problems, Ex. 8 to Ex. 12, CPLEX was not able to solve the problem after 3 hours. However, the proposed three-phase solution method could solve all of them in a very short time, so that Ex. 8, 9, and 10 were solved in less than 1 second, and Ex. 11 and 12 were solved in less than 2 minutes;

b) Increasing the cancellation cost reduces the number of cancelled trains. Furthermore, for the mathematical model, when cancellation cost is increased, CPLEX needs to make more effort to achieve the optimal solution, which leads to an increase in solving time;

c) The less the value of the "Effect ratio" gets, the fewer the rescheduled trains, and in turn, the greater the total rescheduling cost will be. In other words, determination of affecting threshold is a trade-off between the total rescheduling cost and the revival time of the primary timetable. Therefore, for the conditions in which, the central traffic control tends to revive the primary timetable faster, it is required to spend more costs and vice versa. Of course, this trade-off is more significant in cases of large-scale problems;

d) A slight percentage of the total solving time is expended by Phase II (0.01 to $5 \%)$. However, in some problems, a suitable upper bound is provided in this phase, which is very advantageous to speed up the procedure of Phase III.

For each problem, the train timetable graphs can be achieved. In Figure 6, the graphs related to Ex. 9 and Ex. 10 are illustrated. Note that the trains departed after Affecting Threshold (AT) are considered unchanged.

\subsection{Evaluation of heuristic beam search technique}

To evaluate the effectiveness of the heuristic beam search technique (B.S.T.2), several large-scale problems based on Tehran-Mashhad railway corridor have been investigated. To solve the problems, the exact three-phase solution method and both the beam search techniques are used. The parameters $f_{1}$ and $f_{2}$, used in the heuristic technique, have taken different 


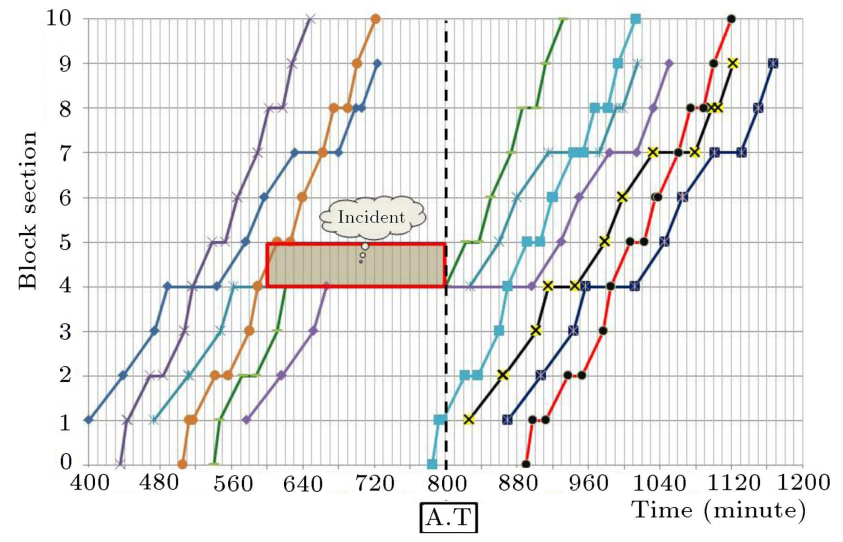

(a)

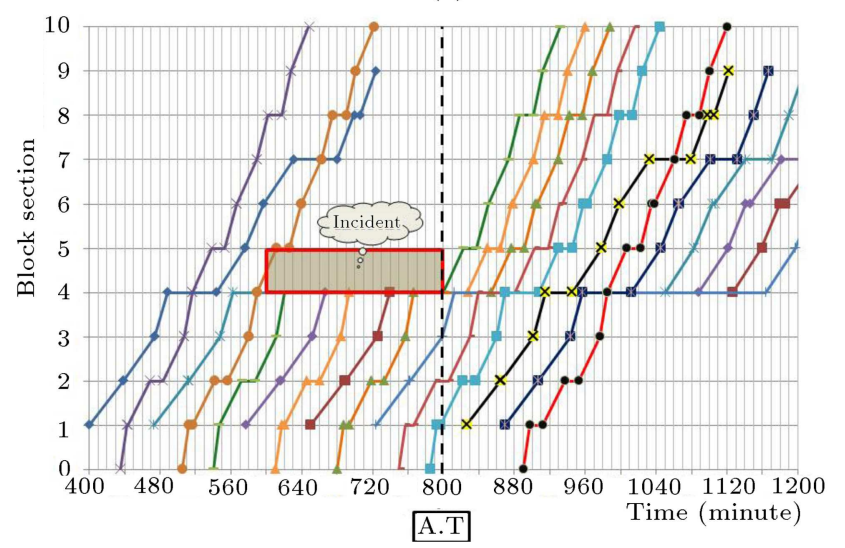

(b)

Figure 6. The rescheduling graphs generated by the proposed solution method: (a) Example 9, and (b) Example 10.

values. Table 3 shows the results. In this table, both total rescheduling cost and solving time are presented.

According to the results shown by Table 3, although the heuristic beam search technique does not necessarily find the optimal solution, it can effectively reduce the solving times of the problems. The amount of such a reduction directly depends on the values of both parameters $f_{1}$ and $f_{2}$. For each of the problems presented in Table 3 , three values of $0.2,0.5$, and 0.8 and two values of 1 and 2 are considered for parameters $f_{1}$ and $f_{2}$, respectively. Figure 7 graphically shows the effects of changing these parameters in both total rescheduling cost and solving time for Ex. 7. In this figure, the upper and the lower parts of the diagram show the results of solving times and total rescheduling costs, respectively. This figure shows that the substantial reduction in solving times is in exchange for slight increase of 3 to $14 \%$ in total rescheduling costs, compared to the optimal ones.

It is also understood from Table 3 that both exact solution method and B.S.T.1 are not able to solve some large-scale problems; since for them, the B\&B tree is so large that leads to "Out of Memory error" (Ex.

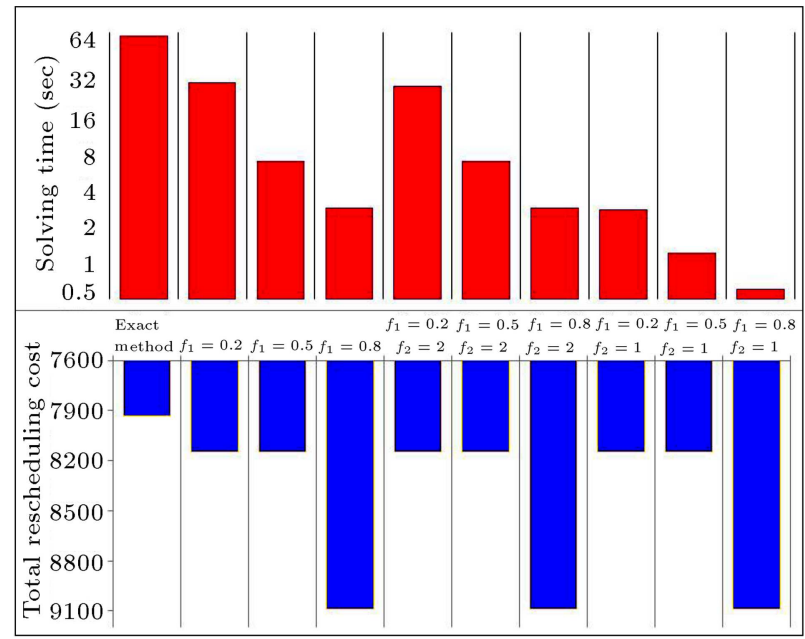

Figure 7. Effect of changing parameters used in the heuristic algorithm for Ex. 7.

3, 4, 5, 8, and 9). However, by applying B.S.T.2, the convenient feasible solutions have been obtained, because of controlling the memory usage. According to the results, either increase of $f_{1}$ or reduction of $f_{2}$ would reduce the amounts of solving times. It is worth mentioning that although the increase of $f_{2}$ would definitely enhance the solving time, it does not necessarily improve the solution achieved. The reason is that some nodes containing good solutions may be fathomed due to such an increase. However, in most cases, increasing the threshold value would result in the improvement of the solution.

\section{Conclusions}

In this study, a new train rescheduling approach named "Restriction Rescheduling Approach" is proposed. The approach simultaneously incorporates three rescheduling policies: cancelling, delaying, and re-ordering. Based on this approach, a mathematical model and an exact solution method are developed. The method consists of three phases. In the first phase, a B\&B algorithm was applied to solve the problem with the assumption of no-train cancellation. In Phase II, based on each combination of the cancellable trains, different sub-problems were created, which were solved using a new algorithm called LLS. In this phase, a suitable upper bound was provided, which is very advantageous to speed up the procedure applied in Phase III. In Phase III, each of the sub-problems was solved by B\&B algorithm. The output of Phase III was the optimal solution of the problem.

Moreover, a heuristic beam search technique was proposed in this article to tackle the large-scale problems. The technique restricts the length of the active node list to avoid growing the B\&B tree as much as possible. An experimental analysis was carried out on the two Iranian double-track railway corridors. 
Table 3. The results of experimental problems in Tehran-Mashhad railway corridor.

\begin{tabular}{|c|c|c|c|c|c|c|c|c|c|c|c|}
\hline \multicolumn{3}{|c|}{ Examples } & Ex. ${ }^{*} 1$ & Ex. 2 & Ex. 3 & Ex. 4 & Ex. 5 & Ex. 6 & Ex. 7 & Ex. 8 & Ex. 9 \\
\hline \multicolumn{3}{|c|}{ Num. of block sections } & 49 & 49 & 49 & 49 & 49 & 49 & 49 & 49 & 49 \\
\hline \multicolumn{3}{|c|}{ Num. of trains } & 10 & 10 & 10 & 12 & 12 & 12 & 13 & 15 & 20 \\
\hline \multicolumn{3}{|c|}{ BOI (min) } & 400 & 400 & 400 & 450 & 450 & 500 & 500 & 500 & 500 \\
\hline \multicolumn{3}{|c|}{ EOI (min) } & 475 & 475 & 475 & 600 & 600 & 600 & 600 & 600 & 600 \\
\hline \multicolumn{3}{|c|}{$\hat{b}$} & $\# 6$ & $\# 6$ & $\# 6$ & $\# 5$ & $\# 5$ & $\# 4$ & $\# 4$ & $\# 4$ & $\# 4$ \\
\hline \multicolumn{3}{|c|}{ Cost Ratio (CR) } & 3000 & 3000 & 3000 & 3000 & 3000 & 1000 & 1000 & 1000 & 1000 \\
\hline \multicolumn{3}{|c|}{ Effect Ratio (ER) } & 1 & 1.5 & 2 & 0.5 & 1 & 1 & 1 & 1 & 1 \\
\hline \multicolumn{3}{|c|}{ Num. of rescheduled trains } & 8 & 9 & 10 & 10 & 12 & 12 & 13 & 15 & 18 \\
\hline \multirow{10}{*}{ 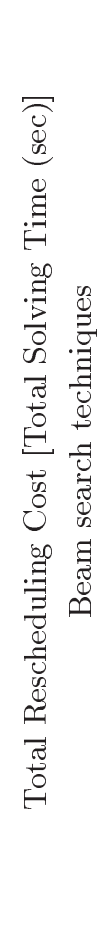 } & & $\begin{array}{c}\text { Exact } \\
\text { solution } \\
\text { method }\end{array}$ & $\begin{array}{l}15104 \\
{[2.99]}\end{array}$ & $\begin{array}{c}15104 \\
{[120]}\end{array}$ & $* *$ & $* *$ & $* *$ & $\begin{array}{l}6773 \\
{[0.5]}\end{array}$ & $\begin{array}{c}7928 \\
{[73.9]}\end{array}$ & $* *$ & $* *$ \\
\hline & & $f_{1}=0.2$ & $\begin{array}{c}15104 \\
{[1.8]}\end{array}$ & $\begin{array}{l}15104 \\
{[65.1]}\end{array}$ & $* *$ & $* *$ & $* *$ & $\begin{array}{c}6773 \\
{[0.36]}\end{array}$ & $\begin{array}{c}8147 \\
{[30.7]}\end{array}$ & $* *$ & $* *$ \\
\hline & $\begin{array}{l}\overrightarrow{1} \\
\ddot{H} \\
\dot{3}\end{array}$ & $f_{1}=0.5$ & $\begin{array}{l}15104 \\
{[0.65]}\end{array}$ & $\begin{array}{l}15104 \\
{[18.9]}\end{array}$ & $* *$ & $* *$ & $* *$ & $\begin{array}{c}6773 \\
{[0.16]}\end{array}$ & $\begin{array}{l}8147 \\
{[6.9]}\end{array}$ & $* *$ & $* *$ \\
\hline & $\dot{\varphi}$ & $f_{1}=0.8$ & $\begin{array}{l}15104 \\
{[0.25]}\end{array}$ & $\begin{array}{l}18303 \\
{[5.94]}\end{array}$ & $\begin{array}{l}15104 \\
{[1113]}\end{array}$ & $* *$ & $* *$ & $\begin{array}{c}7448 \\
{[0.08]}\end{array}$ & $\begin{array}{l}9090 \\
{[2.8]}\end{array}$ & $* *$ & $* *$ \\
\hline & & $f_{1}=0.2 f_{2}=2$ & $\begin{array}{c}15104 \\
{[1.7]} \\
\end{array}$ & $\begin{array}{l}15104 \\
{[17.2]}\end{array}$ & $\begin{array}{l}15104 \\
{[17.1]}\end{array}$ & $\begin{array}{c}90405 \\
{[981]} \\
\end{array}$ & $\begin{array}{l}58901 \\
{[2212]}\end{array}$ & $\begin{array}{c}6773 \\
{[0.33]}\end{array}$ & $\begin{array}{c}8147 \\
{[28.6]}\end{array}$ & $\begin{array}{l}8859 \\
{[676]}\end{array}$ & $* * *$ \\
\hline & & $f_{1}=0.5 f_{2}=2$ & $\begin{array}{l}15104 \\
{[0.62]}\end{array}$ & $\begin{array}{c}15104 \\
{[8.4]} \\
\end{array}$ & $\begin{array}{c}15104 \\
{[8.3]} \\
\end{array}$ & $\begin{array}{c}95530 \\
{[705]} \\
\end{array}$ & $\begin{array}{l}58901 \\
{[1322]}\end{array}$ & $\begin{array}{l}6773 \\
{[0.2]} \\
\end{array}$ & $\begin{array}{l}8147 \\
{[6.9]} \\
\end{array}$ & $\begin{array}{l}10270 \\
{[72.5]}\end{array}$ & $* * *$ \\
\hline & 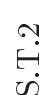 & $f_{1}=0.8 f_{2}=2$ & $\begin{array}{l}15104 \\
{[0.23]}\end{array}$ & $\begin{array}{c}18303 \\
{[5.7]} \\
\end{array}$ & $\begin{array}{c}18303 \\
{[6.1]} \\
\end{array}$ & $\begin{array}{c}90413 \\
{[302]} \\
\end{array}$ & $\begin{array}{c}58901 \\
{[262]} \\
\end{array}$ & $\begin{array}{c}7448 \\
{[0.08]}\end{array}$ & $\begin{array}{l}9090 \\
{[2.8]} \\
\end{array}$ & $\begin{array}{l}10270 \\
{[72.5]}\end{array}$ & $* * *$ \\
\hline & 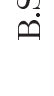 & $f_{1}=0.2 f_{2}=1$ & $\begin{array}{c}15104 \\
{[1.3]} \\
\end{array}$ & $\begin{array}{c}15733 \\
{[2.5]} \\
\end{array}$ & $\begin{array}{c}15163 \\
{[8.3]} \\
\end{array}$ & $\begin{array}{l}89644 \\
{[66.2]}\end{array}$ & $\begin{array}{c}65398 \\
{[144]} \\
\end{array}$ & $\begin{array}{c}6773 \\
{[0.31]}\end{array}$ & $\begin{array}{l}8147 \\
{[2.7]} \\
\end{array}$ & $\begin{array}{c}8859 \\
{[36.2]}\end{array}$ & $\begin{array}{r}13134 \\
{[11302]}\end{array}$ \\
\hline & & $f_{1}=0.5 \quad f_{2}=1$ & $\begin{array}{c}15104 \\
{[0.5]} \\
\end{array}$ & $\begin{array}{l}15733 \\
{[0.95]}\end{array}$ & $\begin{array}{c}19064 \\
{[2.6]} \\
\end{array}$ & $\begin{array}{l}93672 \\
{[41.7]}\end{array}$ & $\begin{array}{l}61573 \\
{[53.9]}\end{array}$ & $\begin{array}{c}6773 \\
{[0.14]}\end{array}$ & $\begin{array}{l}8147 \\
{[1.2]} \\
\end{array}$ & $\begin{array}{l}10270 \\
{[10.8]}\end{array}$ & $\begin{array}{l}13134 \\
{[4339]}\end{array}$ \\
\hline & & $f_{1}=0.8 f_{2}=1$ & $\begin{array}{l}18303 \\
{[0.26]}\end{array}$ & $\begin{array}{c}18303 \\
{[0.5]}\end{array}$ & $\begin{array}{c}19064 \\
{[0.7]}\end{array}$ & $\begin{array}{l}93681 \\
{[15.5]}\end{array}$ & $\begin{array}{l}65119 \\
{[11.9]}\end{array}$ & $\begin{array}{c}7448 \\
{[0.08]}\end{array}$ & $\begin{array}{c}9090 \\
{[0.67]}\end{array}$ & $\begin{array}{l}9510 \\
{[3.2]}\end{array}$ & $\begin{array}{c}22697 \\
{[414]}\end{array}$ \\
\hline
\end{tabular}

*Ex.: Example; ** Not found solution due to "Out of Memory Error";

*** Not found solution after 5 hours.

The results of problems based on Bafgh-Sirjan railway corridor demonstrate the great capability of three-phase solution method in terms of solving time required to find the optimal solution, in comparison with CPLEX 11 software package. For some problems, CPLEX could not achieve the optimal solution after 3 hours, whereas the proposed three-phase solution method could optimally solve them in less than 2 minutes. Evidence was also provided that increase in the cost of train cancellation eventuates in the reduction in the number of the cancelled trains, along with the increase of the train delays and the computation times.

The results of problems based on TehranMashhad railway corridor demonstrate the ability of the heuristic beam search technique to control the size of $\mathrm{B} \& \mathrm{~B}$ tree, which obtains the convenient feasible solutions in shorter times compared to the exact solution method.

\section{References}

1. Hansen, I.A. "Railway network timetabling and dynamic traffic management", International Journal of Civil Engineering, 8(1), pp. 19-32 (2010).

2. Yaghini, M., Nikoo, N. and Ahadi, H.R. "An integer programming model for analysing impacts of different train types on railway line capacity", Transport, 29(1), pp. 28-35 (2014).

3. Xu, J., Zhang, Z. and Mookerjee, V. "Applying bi-random MODM model to navigation coordinated scheduling: a case study of three Gorges project", Transport, 28(2), pp. 140-157 (2013).

4. Chen, C., Zeng, Q. and Zhang, Z. "An integrating scheduling model for mixed cross-operation in container terminals", Transport, 27(4), pp. 405-413 (2012).

5. Spliet, R., Gabor, A.F. and Dekker, R. "The vehicle 
rescheduling problem", Computers and Operations Research, 43, pp. 129-136 (2014).

6. Veelenturf, L.P. "Railway crew rescheduling with retiming", Transportation Research. C, 20(1), pp. 95-110 (2012).

7. Alwadood, Z., Shuib, A. and Abd Hamid, N. "Mathematical rescheduling models for railway services", International Journal of Mathematical, Computational, Physical and Quantum Engineering., 7(8), pp. 798-803 (2013).

8. Cacchiani, V., Huisman, D., Kidd, M., Kroon, L., Toth, P., Veelenturf, L. and Wagenaar, L. "An overview of recovery models and algorithms for realtime railway rescheduling", Transportation Research Part B, 63, pp. 15-37 (2014).

9. Alwadood, Z., Shuib, A. and Abd. Hamid, N. "A review on quantitative models in railway rescheduling", International Journal of Scientific \& Engineering Research, 3(6), pp. 1-7 (2012).

10. Yaghini, M., Momeni, M. and Sarmadi, M. "Solving train formation problem using simulated annealing algorithm in a simplex framework", Journal of Advanced Transportation, 48(5), pp. 402-416 (2014).

11. D'Ariano, A. "Innovative decision support system for railway traffic control", IEEE Intelligent Transportation System Magazine, 1(4), pp. 8-16 (2009).

12. D'Ariano, A., D’Urgolo, P., Pacciarelli, D. and Pranzo, M. "Optimal sequencing of aircrafts take-off and landing at a busy airport", in Proceeding of $13 \mathrm{th}$ International IEEE Conference on Intelligent Transportation System, Madeira Island, Portugal, pp. 15691574 (2010).

13. Corman, F., D'Ariano, A., Hansen, I., Pacciarelli, D. and Pranzo, M. "Dispatching trains during seriously disrupted traffic situations", in Proceeding of 8th IEEE International Conference on Network, Sensing and Control, Delft, The Netherlands, pp. 323-328 (2011).

14. D'Ariano, A., Pranzo, M. and Hansen, I. "Conflict resolution and train speed coordination solving realtime timetable perturbations", IEEE Transaction on Intelligent Transportation System., 8(2), pp. 208-222 (2007).

15. Tornquist, J. and Persson, J. "N-tracked railway traffic rescheduling during disturbances", Transportation Research Part B, 41(3), pp. 342-362 (2007).

16. Burdett, R.L. and Kozan, E. "Techniques for inserting additional trains into existing timetables", Transportation Research Part B, 43, pp. 821-836 (2009).

17. Sato, K. and Fukumura, N. "An algorithm for freight train driver rescheduling in disruption situations", $Q R$ of RTRI, 51(2), pp. 72-76 (2010).

18. Cacchiani, V. and Caprara, A. "Scheduling extra freight trains on railway networks", Transportation Research Part B, 44(2), pp. 215-231 (2010).
19. D'Ariano, A. "Improving real-time train dispatching performance: Optimization models and algorithms for re-timing, re-ordering and local re-routing", 4OR: $A$ Quarterly Journal of Operations Research, 8(4), pp. 429-432 (2010).

20. Mu, S. and Dessouky, M. "Scheduling freight trains traveling on complex networks", Transportation Research part B, 45(7), pp. 1103-1123 (2011).

21. Caimi, G., Fuchsberger, M., Laumanns, M. and Lüthi, M. "A model predictive control approach for discretetime rescheduling in complex central railway station areas", Computers and Operations Research, 39(11), pp. 2578-2593 (2011).

22. Corman, F., D'Ariano, A. and Pacciarelli, D. "Biobjective conflict detection and resolution in railway traffic management", Transportation Research part C, 20(1), pp. 79-94 (2012).

23. Sato, K. and Fukumura, N. "Real-time freight locomotive rescheduling and uncovered train detection during disruption", European Journal of Operational Research, 221(3), pp. 636-648 (2012).

24. Albrecht, A.R., Panton, D.M. and Lee, D.H. "Rescheduling rail networks with maintenance disruptions using problem space search", Computers and Operations Research, 40(3), pp. 703-712 (2013).

25. Dündar, S. and Şahin, İ. "Train re-scheduling with genetic algorithms and artificial neural networks for single-track railways", Transportation Research Part C: Emerging Technologies, 27, pp. 1-15 (2013).

26. Louwerse, I. and Huisman, D. "Adjusting a railway timetable in case of partial or complete blockades", European Journal of Operational Research, 235(3), pp. 583-593 (2014).

27. Pellegrini, P., Marlière, G. and Rodriguez, J. "Optimal train routing and scheduling for managing traffic perturbations in complex junctions", Transportation Research Part B, 59, pp. 58-80 (2014).

28. Wang, Y., Schutter, B.D., Boom, T. and Ning, B. "Optimal trajectory planning for trains under fixed and moving signalling systems using mixed integer linear programming", Control Engineering Practice, 22, pp. 44-56 (2014).

29. Veelenturf, L., Kidd, M., Cacchiani, V., Kroon, L.G. and Toth, P. "A Railway timetable rescheduling approach for handling large scale disruptions", ERIM Report Series Reference No. ERS-2014-010-LIS. Available at SSRN: http://ssrn.com/abstract $=2472934$.

30. Kang, L., Wu, J., Sun, H., Zhu, X. and Wang, Bo. "A practical model for last train rescheduling with train delay in urban railway transit networks", Omega, 50, pp. 29-42 (2015).

31. Zhan, S., Kroon, L.G., Veelenturf, L.P. and Wagenaar, J. "Real-time high-speed train rescheduling in case of a complete blockade", Transportation Research Part B: Methodological, 78, pp. 182-201 (2015). 
32. D'Ariano, A., Pacciarelli, D. and Pranzo, M. "A branch and bound algorithm for scheduling trains in a railway network", European Journal of Operational Research, $\mathbf{1 8 3}(2)$, pp. 643-657 (2007).

33. Tamannaei, M., Saffarzadeh, M., Jamili, A. and Seyedabrishami, S.E. "A novel train rescheduling approach in double-track railways: optimization model and solution method based on simulated annealing algorithm", International Journal of Civil Engineering, 14(3), pp. 139-150 (2016).

34. Tamannaei, M., Saffarzadeh, M., Jamili, A., Seyedabrishami, S.E. and Bagheri, S.R., Proposing a New Train Rescheduling Approach with Simultaneous Consideration of Cancelling, Delaying and Re-ordering Policies, in Transportation Research Board (TRB), Washington, United States (2015).

35. AitZai, A. and Boudhar, M. "Parallel branch-andbound and parallel PSO algorithms for job shop scheduling problem with blocking", International Journal of Operational Research, 16(1), pp. 14-37 (2013).

36. Shafia, M.A., Pourseyed Aghaee, M., Sadjadi, S.J. and Jamili, A. "Robust train timetabling problem: mathematical model and branch and bound algorithm", IEEE Transaction on Intelligent Transportation System, 13(1), pp. 307-317 (2012).

37. Caprara, A., Fischetti, M. and Toth, P. "Modelling and solving the train timetabling problem", Operations Research, 50(5), pp. 851-861 (2002).

38. D'Ariano, A. "Improving real-time train dispatching: models, algorithms and applications", PhD Thesis, Series no. T2008/6, the Netherlands TRAIL Research School (2008).
39. Jafari, N. and Zegordi, S.H. "Simultaneous recovery model for aircraft and passengers", Journal of Franklin Institute, 348(7), pp. 1638-1655 (2011).

\section{Biographies}

Mohammad Tamannaei is an Assistant Professor in Faculty of Transportation, Isfahan University of Technology, Isfahan, Iran. His current research interests include transportation planning, mathematical optimization, railway engineering and traffic engineering. He has published several papers.

Mahmoud Saffarzadeh is a Professor in Faculty of Civil and Environmental Engineering, Tarbiat Modares University, Tehran, Iran. He obtained his PhD degree in Transportation Engineering from Carleton University, Ottawa, 1995. His research areas include: intelligent transportation system, planning \& design of airports, transportation terminals, traffic engineering, transportation safety, advanced highway design.

Amin Jamili is an Assistant Professor in Department of Industrial Engineering, University of Tehran, Iran. His research areas include production systems and mathematical modelling. His expertise includes optimization, scheduling, and energy management.

Seyed Ehsan Seyedabrishami is an Assistant Professor in Faculty of Civil and Environmental Engineering, Tarbiat Modares University, Tehran, Iran. His research areas include: transportation planning, transportation demand, and mathematical optimization. 